\section{A new flexible and homogeneous device for photodynamic treatment of actinic keratosis}

E. Thecua ${ }^{1, *}$, J.-B. Tylcz ${ }^{1}$, C. Vicentini ${ }^{1,2}$,

L. Mortier $^{1,2}$, R.-M. Szeimies ${ }^{3}$, S. Mordon

${ }^{1}$ University Lille, INSERM, CHU Lille, U1189 - ONCO-THAI - Image Assisted Laser

Oncology, Lille, France Therapy for

${ }^{2}$ Department of Dermatology, CHU Lille, France

${ }^{3}$ Department of Dermatology \& Allergology, Knappschaftskrankenhaus Recklinghausen,

Germany

Actinic keratosis are common pre-cancerous lesions of the skin induced by sun damages and are usually present on the scalp, shoulders or arms of the patients. In some cases actinic keratosis are multiple and confluent and can therefore be defined as cancerous field. A current recommendation of the International Society for Photodynamic Therapy in Dermatology has led to the decision to treat these lesions before they turn into tumor and since many years now, photodynamic therapy is one of the first line treatments [1].

However, the classical light sources used for the photodynamic treatment of such lesions are usually planar while the targeted surfaces are mainly curvy (due to the human body shape) that leads to an inhomogeneous light distribution, which is a one of the causes for the clinical results variability [2]. Moreover, photodynamic ther-apy is known to be very painful and may force the patient to ask for premature end of treatment [3].
Recently, a new modality of photodynamic therapy for the treatment of actinic keratosis was proposed and for which the light source is nothing less than the Sun. The first claimed advantage is that the nature of the light source guaranties a homogeneous light distribution on the treated lesions. Despite this benefit, daylight photodynamic treatments cannot be performed if outside temper-ature is below $10^{\circ}$ $\mathrm{C}$ or if it is rainy [4].

To overcome the hereinbefore drawbacks, a new device based on light emitting fabric is proposed. Optical fibers are knitted to build a flexible structure that produces homogeneous light. The fabrics are embedded within an adjustable plastic helmet and illuminated by a fractionated LASER source. As for daylight treatments, the low delivered irradiance $\left(4 \mathrm{~mW} / \mathrm{cm}^{2}\right)$ ensure a significant pain reduction. The proposed device delivers a total light dose of $12 \mathrm{~J} / \mathrm{cm}^{2}$, instead of $37 \mathrm{~J} / \mathrm{cm}^{2}$ which efficiency is being assessed in a bi-centric clinical trial.

\section{References}

[1] C.A. Morton, R.-M. Szeimies, A. Sidoroff, L.R. Braathen, J. Eur. Acad. Dermatol. Venereol. 27 (2013) 536-544.

[2] H. Mosely, Photochem. Photobiol. Sci. 4 (2005) 911-914.

[3] D. Farhi, C. Bedane, J. Savary, N. Basset-Seguin, Eur. J. Dermatol. 23 (1) (2013) 68-76.

[4] S.R. Wiegell, M. Hædersdal, P.A. Philipsen, P. Eriksen, C.D. Enk, H.C. Wulf, Br. J. Dermatol. 158 (2008) 740-746.

http://dx.doi.org/10.1016/j.pdpdt.2017.01.042 